\title{
Arbor
}

\section{El socialismo madrileño hace un siglo: Un anhelo de reformas.}

\section{Santiago Castillo}

Arbor CLXIX, 666 (Junio 2001), 411-429 pp.

\section{Introducción}

Dos ideas básicas subyacen en este texto. Los años 1900-1904 marcan el inicio en España de un proceso sistemático de promulgación de textos normativos en materia laboral y de creación de instituciones y cauces para su aplicación. Es decir, comienza el intervencionismo legal del Estado en la cuestión obrera. Coincidiendo con el cambio también se detecta, en el movimiento socialista español en general y en el madrileño en particular, la cristalización de una estrategia reformista coincidente con el inicio de un significativo despegue en cuanto a su implantación.

A la puesta en relación de ambas cuestiones dedicaremos las siguientes páginas.

\section{Notas sobre el socialismo madrileño}

Partamos de algunas consideraciones genéricas. Es sabido que el socialismo español en su doble vertiente política y sindical tuvo un desarrollo muy precario durante el XIX ${ }^{1}$. Como hemos descrito en otro lugar, el lento tejer y destejer de núcleos del PSOE conlleva el que de las 22 agrupaciones existentes en el Congreso fundacional se llegue a fin de siglo con $53^{2}$. No es muy diferente la evolución de las cifras sindicales: los 5.000 afiliados de 1888 no superarán los 8.000 hasta el despegue iniciado en $1899^{3}$. 
Es precisamente a finales de siglo cuando se aprecia un incremento sustancial en ambas estructuras comenzando lo que hemos denominado el tránsito hacia la mayoría de edad que, creemos, se adquiere tanto por el socialismo como por el movimiento obrero español en general en la segunda década del $\mathrm{XX}^{4}$.

¿Cuál había sido el desarrollo del socialismo madrileño dentro de esta evolución? El tejido asociativo del Madrid de finales de siglo no era muy amplio ni tupido en cuanto a organizaciones propiamente obreras y, dentro de ellas, menos a las dedicadas a la resistencia. En todo caso en tal panorama, el asociacionismo socialista venía pugnando por adquirir un protagonismo que sólo con el cambio de siglo iba a ser determinante.

Es, por demás, conocido el papel relevante de los fundadores madrileños en el inicio del socialismo español: Desde la escisión de la I Internacional, 1873, hasta la creación del primer núcleo del partido, 1879; en las negociaciones de los primeros programas con los societarios catalanes, 1880-82, y su enfrentamiento a las tácticas anarquistas; al aglutinar después a los grupos dispersos a través de un semanario, El Socialista, 1886, hasta conseguir constituir un partido político y una Unión sindical, ambos de ámbito nacional, 1888, por muy exigua que fuese su implantación... ${ }^{5}$.

No insistiremos, aquí, en tales temas. Nos centraremos en algo que suele ser menos conocido: al par que realizaban las labores descritas, ¿cómo les fueron las cosas en el ámbito concreto de la capital del Estado?

Realizaremos tal aproximación en torno a un indicador poco utilizado: la capacidad de creación de Centros Obreros y su mantenimiento. A través de los Centros podremos ir dibujando ese largo trayecto recorrido en la recluta de adeptos. Desde el no muy gran éxito obtenido en sus primeros años, hasta el inicio de tiempos mejores en las postrimerías del siglo.

El periplo iba a ser largo. En sus prolegómenos podemos considerar aquella reducida habitación, alquilada por 15 pesetas, en un tercer piso de la calle Salitre, donde uno o dos armarios, algunos bancos y una mesa componían la sede de una Asociación del Arte de Imprimir que desde 1874 pasaría diferentes vicisitudes: afrontar una situación de recesión de afiliados; vender la imprenta cooperativa y reactivar la caja de resistencia... Es decir iniciar un proceso de consolidación como sindicato reivindicativo y solidario que pasaría por recuperar la afiliación y luego afianzarse. Con momentos culmen como cuando, en junio de 1880, se aprobaba - no sin reñida pugna - el envío de 1.500 pesetas de sus arcas a los tipógrafos huelguistas milaneses ${ }^{6}$. 
El socialismo madrileño hace un siglo: Un anhelo.....

Pequeño espacio el de esta sede que era testigo de todo un gran vuelco: una organización obrera transitaba de una visión armonicista prevalente, a la solidaridad en el conflicto de clases. Y lo hacía pilotada por un granado equipo de personas procedentes en gran parte de la proscrita Internacional, cuya dirección asumía un joven tipógrafo llamado Pablo Iglesias. Los Sedano, Gómez Latorre, Nafarrete, García Quejido, Bermejo y algunos otros que, al par que reorientaban un sindicato, fundaban en la clandestinidad, en 1879, el primer núcleo del futuro PSOE y seguían en su mayoría en activo en ambas estructuras a finales del XIX.

Esos mismos dirigentes se habían de plantear en 1882 la búsqueda de nueva sede para un Arte consolidado en torno a los 1.000 afiliados $\mathrm{y}$ algunas pequeñas asociaciones -carpinteros, trabajadores en hierroque nacían al calor de la huelga tipográfica mantenida ese año. Se ubicarían en un principal algo más espacioso que, por doble precio que el anterior, se alquilaba en la calle Amor de Dios.

Serían años de paciente y continuada actividad. Discusiones con el anarquismo en las Escuelas Pías de San Antón a fines de 1883 y principios de 1884. En ellas habrían de emplearse a fondo Abascal, García Quejido, Aparicio, San Miguel, Gómez Crespo y, por supuesto, Iglesias, contendiendo en torno a qué organización debía adoptar la clase obrera para su emancipación.

Mayor trascendencia a la opinión pública tendrían sus informes orales y escritos ante la Comisión de Reformas Sociales, 1884-5. Actuaciones como las de Quejido y Gómez Latorre, también las de Abascal, Sedano, Pauly, Nafarrete, Serna o Perezagua por las entidades sindicales junto a la de Iglesias en nombre del partido, tendrían amplia resonancia.

Como ya indicamos hace tiempo, para el corto número de adeptos sobre los que influía, el socialismo madrileño había sabido rentabilizar las informaciones obreras actuando con unidad y método ${ }^{7}$.

Asistimos, pues, a las primeras salidas a la luz, de forma constante, de los líderes socialistas en su vertiente de críticos del sistema, organizadores sindicales y competidores de otras opciones obreras, como el anarquismo. Su papel se verá reforzado por el traslado obligado del Comité Central de la Federación Nacional Tipográfica de Barcelona a Madrid en diciembre de 1884. Al año siguiente, Iglesias con García Quejido se responsabilizarían de dicho Comité y de la organización tipográfica a escala nacional ${ }^{8}$.

$\mathrm{Y}$ es precisamente al final del 85 cuando se producirá un hecho que marcará drásticamente el futuro. Nos referimos a la huelga de la Casa Ribadeneyra en Madrid. La derrota obrera provocará una 
amplia diáspora de tipógrafos socialistas en busca de trabajo por toda España: Alarcón, Quejido, Alvaro Ortiz, Abascal... Su emigración significaría un amplio impulso a la implantación de las estructuras sindicales y del partido en diversos lugares. Aunque, para el caso madrileño, fuese a corto plazo una dura sangría, máxime en un momento en que se buscaban nuevos horizontes en otra sede - por 83 pts. mesen la calle Jardines 32 , piso $1^{\circ}$.

No obstante, los oficios asociados en la nueva sede, se verían pronto apoyados por un semanario, El Socialista,1886, que aún residiendo, como la agrupación socialista, fuera del Centro, eran propiedad de accionistas que también estaban afiliados a sus sociedades. El periódico iba a tener un papel fundamental en el desarrollo de un socialismo que acababa por configurarse con la constitución definitiva del PSOE y la UGT, en agosto de 1888 y su vinculación a la $\mathrm{II}^{\mathrm{a}}$ Internacional en el Congreso fundacional de Paris del año siguiente con la consiguiente entrada en la dinámica de los $1^{\text {os }}$ de mayo ${ }^{9}$.

La escala del socialismo madrileño obviamente iba en aumento y parecía llegado el momento de abandonar la etapa de sedes en pisos - locales en alquiler donde ubicar las secretarías de las sociedades.

En 1892 la situación se vivía ya como angustiosa. Tras los efectos de los $1^{\circ}$ de mayo, en el local de la calle Jardines no cabían las sociedades existentes. Pese a que los trabajadores en hierro y los doradores tenían su sede fuera, la decena de secretarías allí ubicadas se hallaban hacinadas en reducido espacio... Las doce sociedades más el Montepio de Tipógrafos y el Comité Central Tipográfico necesitaban nuevo espacio.

Tras amplia búsqueda por todo el Madrid popular, la solución se hallaría en la misma calle Jardines. En el $n^{0} 20$, se había detectado la existencia de dos locales el principal derecha y el izquierda. Si ambas piezas se unían podría diseñarse un nuevo Centro. La aquiescencia del casero se tenía. Sólo quedaba derribar y mover tabiques, con el trabajo gratuito de los albañiles asociados. El empapelado posterior sería cosa de los decoradores. Los carpinteros se afanarían en levantar un estrado y construir los bancos para el salón de reuniones... El primer Centro Obrero digno de tal nombre, se inauguraría, así, en julio de $1892^{10}$.

En setiembre ya servía de sede a un Congreso obrero de ámbito nacional: el $\mathrm{VI}^{\circ}$ de la Federación Tipográfica. Dos años después, se desarrollaría allí el $\mathrm{IV}^{\circ}$ Congreso del PSOE, primero de los celebrados por el partido en la capital de España. Allí permanecerían hasta noviembre de 1898, en que otra vez por desbordamiento de efectivos, habría un nuevo cambio.

El Centro de Sociedades Obreras pasaba a radicar entonces en la calle de la Bolsa, 14 principal. Aunque el proceso de fuerte crecimiento 


\section{El socialismo madrileño hace un siglo: Un anhelo....}

del asociacionismo iba a hacer que su vida fuese efímera. Al año, los socialistas contaban con más de 10.000 trabajadores asociados en su esfera de influencia - 6.500 ya en la UGT - véase cuadro $n^{\circ} 1$, y la expansión del asociacionismo no hacía sino comenzar.

CUADRO 1. Organismos que integran el Centro de Sociedades Obreras de Madrid (octubre 1899)

\begin{tabular}{|c|c|}
\hline Sociedades de resistencia & Afiliados \\
\hline Asociación Arte de Imprimir* & 660 \\
\hline Albañiles* & 1.178 \\
\hline Aserradores a brazo & 23 \\
\hline Aserradores mecánicos & 136 \\
\hline Broncistas, latoneros y vidrieros* & 173 \\
\hline Camareros y cocineros & 78 \\
\hline Canteros y marmolistas & 1.420 \\
\hline Carpinteros de armar* & 214 \\
\hline Carpinteros de taller* & 1.299 \\
\hline Constructores de carros & 143 \\
\hline Constructores de carruajes & 352 \\
\hline Ebanistas & 399 \\
\hline Electricistas* & 86 \\
\hline Embaldosadores & 92 \\
\hline Empedradores* & 126 \\
\hline Escultores & 59 \\
\hline Estuquistas* & 48 \\
\hline Fumistas & 127 \\
\hline Hortelanos & 116 \\
\hline Modelistas y fundidores & 198 \\
\hline Mozos de comercio & 69 \\
\hline Obreros en hierro y demás metales* & 660 \\
\hline Panaderos* & 1.575 \\
\hline Pintores-decoradores & 460 \\
\hline Poceros* & 204 \\
\hline Profesiones y oficios varios & 16 \\
\hline Tallistas & 167 \\
\hline Zapateros, cortadoras y guarnecedoras* & 126 \\
\hline Total de afiliados a sociedades de resistencia & \multirow{2}{*}{10.204} \\
\hline Otros organismos & \\
\hline Agrupación socialista & 662 \\
\hline Socorros a obreros de la Imprenta & 304 \\
\hline Montepío obrero & 69 \\
\hline Total otros organismos & 1.035 \\
\hline Total general & 11.170 \\
\hline
\end{tabular}

* Sociedades por enctonces pertenecientes a la UGT. Falta la Sociedad de Fontaneros.

Residían además en el Centro: el Comité Central de la Federación Tipográfica, el recién trasladado Comité Nacional de la UGT y la cooperativa Casa del Pueblo. 
La nueva dinámica exigía espacios mayores y en enero de 1900 se inauguraba otro Centro de mayor capacidad en el $\mathrm{n}^{\circ} 24$ de la calle Relatores. El alquiler se duplicaba - de 225 a 530 ptas. al mespero la nueva sede era necesaria al superar ya el medio centenar las sociedades y la docena de millares el número de asociados - de los que más de 10.000 pertenecían a UGT- véase cuadro $\mathrm{n}^{\circ} 2$.

CUADRO 2. Efectivos de la UGT

\begin{tabular}{|c|c|c|c|c|c|}
\hline \multirow[b]{2}{*}{ Fecha } & \multicolumn{2}{|c|}{ Cifras globales } & \multicolumn{3}{|c|}{ Cifras en Madrid } \\
\hline & Secciones & Afiliados & Secciones & Afiliados & $\%$ Madrid/total \\
\hline 1899, Sep. & 65 & 15.264 & 13 & $* 6.349$ & 41,5 \\
\hline 1900, Mar. & 69 & 14.737 & 17 & 10.310 & 69,6 \\
\hline 1900, Sep. & 126 & 26.088 & & 13.318 & 51 \\
\hline 1901, Feb. & 172 & 29.383 & 30 & 11.358 & 38,6 \\
\hline 1901, Sep. & 198 & 31.558 & 30 & 10.736 & 34 \\
\hline 1902, Feb. & 226 & 32.778 & 34 & 10.604 & 32,3 \\
\hline 1903, Ene. & 282 & 46.896 & 40 & 16.783 & 35,7 \\
\hline 1903, Sep. & 331 & 46.574 & 41 & 15.781 & 33,8 \\
\hline 1904, Mar. & 352 & 56.900 & 41 & 17.072 & 30 \\
\hline 1904 , Oct. & 363 & 55.817 & 47 & 18.151 & 32,5 \\
\hline 1905, Feb. & 373 & 56.905 & 45 & 18.809 & 33 \\
\hline 1905, Oct. & 346 & 46.485 & 39 & 18.861 & 40,5 \\
\hline 1906, Mar. & 274 & 36.557 & 33 & 17.462 & 47,7 \\
\hline 1907, Abr. & 246 & 32.405 & 31 & 17.335 & 53,5 \\
\hline 1907, Sep. & 225 & 30.066 & 32 & 17.201 & 57,2 \\
\hline 1908, Mar. & 240 & 32.612 & 35 & 19.024 & 58,3 \\
\hline 1908 , Oct. & 260 & 39.668 & 45 & 24.882 & 61 \\
\hline 1909, Mar. & 301 & 43.478 & 51 & 26.775 & 61,5 \\
\hline 1909 , Oct. & 307 & 43.562 & 57 & 28.115 & 64,5 \\
\hline
\end{tabular}

Fuente: Elaboración propia sobre datos oficiales.

Este somero recorrido por la historia de los Centros Obreros, permite observar el salto de magnitud en el socialismo finisecular madrileño. Era un fenómeno apreciable en todo el país, como ellos mismos constataban con esperanza, a comienzos del 99: «Hasta aquí las fuerzas 
El socialismo madrileño hace un siglo: Un anhelo.....

socialistas han aumentado con mucha lentitud; a partir de este año crecerán rápidamente» ${ }^{11}$.

Y ciertamente, sería en 1899 , sobre todo una vez restablecidas las garantías constitucionales y levantado el estado de guerra vigente en todo el país, cuando el crecimiento se aprecie de forma muy significativa en toda España. Y dentro de esa onda expansiva del movimiento obrero organizado en general, el socialismo madrileño era, como hemos indicado, por su magnitud un caso relevante. Algunos oficios de la capital de España despegaban de forma drástica. Así la Sociedad de Albañiles El Trabajo, que oscilaba entre los 100 y los 326 afiliados de enero del 98 a enero del 99, pasaba a los 2.448 en igual fecha de 1900 . Crecimiento que aún seguiría con los 3.278 y 3.881 de enero de años siguientes, y tendría un nuevo salto de escala al lograr los $6.030 \mathrm{miem}$ bros en enero de 1903. Iniciaba así una trayectoria que le haría ser el alma mater de la constitución del siguiente Centro Obrero ya en propiedad que sería la Casa del Pueblo en $1908^{12}$.

Pero esa es ya otra etapa del asociacionismo madrileño, inmersa a su vez en una no menos novedosa andadura del socialismo español que superaba la fuerte crisis de afiliación de los años 1906-7 e iniciaba su definitivo despegue.

Retornemos a nuestro final de siglo. En 1899, al par que se daba, como hemos dicho, el arranque de los crecimientos significativos, un nuevo hecho revalorizaría aún más el papel de Madrid en el sindicalismo socialista.

\section{La ubicación en Madrid del Comité Nacional de UGT}

La doble estructura - sindical y política- del socialismo, había cristalizado desde sus inicios en una dualidad de sedes de sus órganos rectores. El Comité Nacional del PSOE radicaba en Madrid y el de la UGT en Barcelona.

Tal situación variaría, sin embargo, en 1899, cuando el VI Congreso de UGT acordaba el traslado de su Comité Nacional a la capital de España.

Los delegados que tomaban tal acuerdo por práctica unanimidad no desconocían, sin duda, la cualidad de Barcelona como centro industrial por antonomasia en España y, por tanto, en teoría, el lugar más idóneo para la residencia del órgano rector de una central obrera. De hecho, allí habían radicado su sede fundacional manteniéndola en sucesivos congresos. 
Pero a la altura de fin de siglo difícil era no aceptar, como habían afirmado los Forjadores y Martilladores de Vizcaya, que Madrid había devenido «el punto más conveniente para dirigir la organización obrera».

Porque en un momento de despegue de la central socialista, su Comité Nacional debía tener una infraestructura de apoyo de cierta solidez para poder gestionar el sindicato con unos mínimos de efectividad, y en Barcelona éstos comenzaban a escasear. Cotizando a la UGT sólo había, en los momentos del VI congreso, 759 afiliados en la provincia de Barcelona, cifra que en febrero del año siguiente descendía a 706. De ellos, sólo cinco sindicatos con un total de 155 afiliados en la capital donde venía residiendo el Comité.

El socialismo barcelonés, por otra parte, no sólo era exiguo, además estaba dividido ${ }^{13}$. En la capital del Principado había dos Centros Obreros de advocación socialista y dos organizaciones del partido con duplicidad de liderazgo. En la situación en que la Unión se hallaba, el lugar más idóneo para el Comité Nacional era a todas luces la çapital de España, tanto por el elevado número de afiliados -recordemos que a poco de finalizado el congreso, Madrid contaba con 6.500 afiliados-, como por los cuadros disponibles. De variar la situación, en próximos congresos cabía modificar la decisión.

Y la situación variaría..., pero en la línea de un deterioro progresivo de la implantación socialista barcelonesa a la par que Madrid se constituía en el bastión más importante de afiliación ugetista. Como ya hemos indicado, la expansión del asociacionismo -más de 10.000 afiliados a la UGT- obligaba, en enero de 1900, a la busqueda de un nuevo Centro Obrero en la calle Relatores. Madrid contaba entonces con el $69 \%$ del total de efectivos de la central sindical. (Véase cuadro $\mathrm{n}^{0} 2$ ).

En Relatores, se ubicaría también el nuevo Comité Nacional elegido tras el Congreso, formado por P. Iglesias, presidente; Vicente Barrio, fontanero, vicepresidente; M. Gómez Latorre, tesorero; Baldomero Huetos, vicetesorero; Antonio García Quejido, secretario; Cipriano Rubio, albañil, vicesecretario. El Comité se iría complementando con un vocal elegido por cada sociedad madrileña afiliada. Entre ellos, por los estuquistas, estaría Francisco Largo Caballero, que en noviembre sustituía como vicetesorero a Huetos.

Todos los citados pertenecían al PSOE. Cuatro de ellos (los tipógrafos Gómez, Iglesias, Huetos y Quejido) desde la época de fundación del partido y de transformación del Arte de Imprimir, veinte años antes. Dos compartían su presencia en los máximos órganos de partido y sindicato - Iglesias y Largo Caballero-, y otros dos - Quejido y Gómez- dejaban cargos en el Comité Nacional del PSOE para asumirlos 
El socialismo madrileño hace un siglo: Un anhelo.....

en el de la UGT ${ }^{14}$. La imbricación de personas en ambos organismos era patente. Con posterioridad, como es sabido, seguiría siéndolo ${ }^{15}$.

El asociacionismo madrileño estaba, pues, en expansión y añadía en sus líderes la representación política y sindical nacional del socialismo.

\section{Planteamientos y actitudes del socialismo finisecular madrileño}

Aunque los objetivos últimos del socialismo eran la abolición de la propiedad privada de los medios de producción y la instauración de una sociedad sin clases, desde sus primeras declaraciones doctrinales, el PSOE establecía la reivindicación de diversas reformas políticas y sociales consideradas como necesarias para el logro de sus aspiraciones últimas. Entre ellas, algunas remitían a la necesidad de su establecimiento por ley. Así, en el programa constituyente del partido (1888) figuraban, entre las políticas, los derechos de asociación, reunión, o el sufragio universal... y, entre las sociales, la jornada legal de ocho horas, la prohibición del trabajo de los niños, el salario mínimo legal e igual para trabajadores de ambos sexos... ${ }^{16}$

Recordemos también que, desde su fundación, la obtención de legislación laboral se decantaba asimismo como elemento central del sindicalismo ugetista. Según los dos primeros artículos de sus estatutos, el «objeto» fundamental de la UGT —organizar la clase obrera y luchar por mejorar sus condiciones de trabajo- habría de lograrse «apelando a la huelga bien organizada y recabando de los poderes públicos cuantas leyes favorezcan los intereses del trabajo, tales como la jornada de ocho horas, fijación de un salario mínimo, igualdad de salario para obreros de uno y otro sexo, etc.» ${ }^{17}$

Los sindicatos, según los socialistas, podían conseguir mejoras en determinadas ocasiones y circunstancias, fuese por la presión de la huelga o por la negociación, si ésta era posible. Pero, para generalizarlas a todos los trabajadores o para que no se perdiesen en un futuro ante una adversa relación de fuerzas, era necesario que las mejoras cristalizasen en leyes y que se impidiese a los patronos conculcarlas. Junto a la acción sindical, pues, había que «acudir al terreno político.»

De la solidez de tales principios da muestra el que, aunque desconfiasen de que existiese voluntad de afrontar reformas por los gobiernos de la Restauración, las dos primeras campañas emprendidas por los socialistas madrileños, $1885-7$, con pretendido ámbito nacional, fueran precisamente ligadas a la obtención de legislación social. 
La primera de dichas campañas la iniciaba el Arte de Imprimir para conseguir la aplicación de la única ley laboral por entonces vigente -la Ley Benot sobre el trabajo de los niños- ${ }^{18}$. En agosto de 1885 dirigían en tal sentido una solicitud a todos los dueños de talleres tipográficos y de encuadernación y a las empresas periodísticas. No obtuvieron respuesta. En septiembre repitieron el envío. Idéntico resultado. No se desanimaron. Con los datos que tenían, presentaron denuncias contra varios industriales en los juzgados municipales. Tampoco tenían éxito. Aún darían otro paso. El 22 de diciembre se entrevistaban con Montero Rios, ministro de Fomento. Este les prometió ocuparse de inmediato del asunto. Promesa vana. También el gobernador civil de Madrid daría la callada por respuesta. La Comisión de Reformas Sociales, por su parte, contestaba con evasivas: «Era un tema planteable».

Agotados estos cauces, el Arte explicaba en un mítin su fracaso y elevaba el 25 de abril del 86 una exposición al presidente del Consejo de Ministros. Al escrito se adherían importantes entidades obreras catalanas: el Centro Obrero de Barcelona y otras 22 sociedades de aquella ciudad y sus contornos. El 21 de mayo, representantes de varios sindicatos entregaban a Sagasta la exposición con las firmas de las sociedades que las apoyaban. Sagasta prometió ocuparse del asunto y... nunca más se supo.

Los socialistas habían mostrado, trámite a trámite durante casi un año, el nulo interés de las autoridades por aplicar una ley vigente. De ahí que no se alarmasen por el fracaso de su segunda campaña, al año siguiente, en pro de una ley que impusiera las ocho horas como jornada de trabajo pese a seguir teniendo amplios apoyos catalanes ${ }^{19}$.

Dos campañas que no obtendrían éxito, dada la parvedad numérica del socialismo entonces, a la que se unía la total desidia, cuando no rechazo, de las fuerzas políticas democráticas y republicanas de la época y el desinterés del Estado por la aplicación de la ley vigente o por el planteamiento de la que, con carácter nuevo, se pedía.

Lejos de cambiar de estrategia, los socialistas se reafirmarán en mantener la acción sindical y la lucha por la legislación social como elementos complementarios en un proceso más o menos largo en función de la capacidad de presión obrera que se fuese obteniendo.

Nada tiene, pues de extraño que tanto PSOE como UGT apoyasen desde sus inicios las manifestaciones del 1 de Mayo, en los términos fijados en el Congreso de 1889 en París, del que surgía la II Internacional Socialista.

El objetivo de tales manifestaciones era claro: que «los trabajadores emplacen a los poderes públicos ante la obligación de reducir legalmente 
a ocho horas la jornada de trabajo y aplicar las demás resoluciones del Congreso Internacional de París». Los socialistas españoles, para cumplirlo no tenían más que ampliar retocando su propio programa reivindicativo.

La efemérides se entendía desde un principio, para los socialistas, como una forma de "presentar ante los ojos de la burguesía el inmenso ejército obrero que ha tomado por bandera la jornada legal de ocho horas y las otras resoluciones» del Congreso de París. De ahí que fuese conveniente facilitar a todos la participación en el acto. Allí donde hubiese fuerza se realizaría el mismo 1 de mayo. Donde, por las causas que fuere, no fuese posible, la festividad más próxima.

En tal planteamiento, lo primordial no era la huelga, sino dirigirse al Estado, en demanda de una serie de leyes que favorezcan a toda la clase obrera. De ahí, su oposición tajante a intentar que los $1^{\circ}$ de mayo se tradujesen en intentos de huelgas generales al modo anarquista.

Con el transcurrir del tiempo, la propuesta socialista -manifestación y peticiones pacíficas - acabaría imponiéndose a otras opciones. Pero en algunos lugares, - y este es el caso de la capital del Estadotriunfaba desde su inicio. En Madrid, el domingo 4 de Mayo de 1890, unos 2.000 trabajadores asistían, en el Liceo Ríus, al mitin presidido por Gómez Latorre y Antonio Torres, con Huetos y Cermeño, como secretarios. Todos ellos tipógrafos en representación del Comité local de la Agrupación socialista. Los oradores sindicales serían José Villares por El Porvenir, de los trabajadores en hierro, Hipólito González por La Unión, de los de la madera, Saturnino González por los albañiles de El Trabajo, Juan J. Morato por el Arte de Imprimir, F. Diego por el Montepio de Tipógrafos, José Castillo, por los Curtidores. Cerraba los discursos Pablo Iglesias en nombre de la Agrupación. Tras el mitin, unos 30.000 manifestantes acompañaban el cortejo, presidido por Iglesias, a entregar en la Presidencia del Gobierno las peticiones obreras para su traslado al Parlamento "para que fuesen traducidas en leyes».

Era, desde luego, un primero de mayo relevante por muchos motivos. Entre ellos el de la manifestación. A partir de 1891, la dura actitud represiva de los sucesivos gobiernos conservadores y fusionistas, llevaba a la prohibición estricta de las manifestaciones del $1^{\circ}$ de mayo en la calle.

En años siguientes, los socialistas iban a ir creando un patrón de actuación prontamente perfilado: Cese del trabajo, si había fuerza suficiente. Traslado de la conmemoración al festivo - domingo- más próximo allá donde no hubiera fuerza como para cesar el trabajo el mismo uno ${ }^{20}$. Aunque, pronto, siguiendo las directrices de los Congresos internacionales se insistiría en la conveniencia de celebrarla el mismo 
día $1^{\circ}$, dándole carácter de Fiesta. Actos en locales públicos, en función de las posibilidades. En Madrid, pronto se añadían las idas y venidas por los paseos de la ciudad —el del Prado, por ejemplo- en pequeñísimos grupos con un lazo, obviamente rojo, en la solapa y, luego, las celebraciones en el campo, dada la prohibición gubernativa de manifestaciones, hasta 1903 en que, por conjunta actuación de partido y sindicatos, conseguirían imponer el derecho de manifestación en la calle ${ }^{21}$.

Y junto a esto, o más bien arropándolo, acrecentamiento del carácter cada vez mayor de Fiesta del Trabajo o de la Paz con la puesta en pie de actividades que en más de una ocasión acabarán generando tradiciones de amplia aceptación y largo alcance. Por ejemplo, las meriendas madrileñas en el campo, la Fuente de la Teja, donde tortillas, arroces, chuletas... comidas al son de organillos, gaitas y guitarras fueron práctica iniciada por los panaderos y rápidamente asumida y trasformada en tradición colectiva por el resto.

La actitud y comportamientos de los socialistas madrileños y/o españoles no divergía en esto de los de sus correligionarios de otros países con quienes estaban en estrecha vinculación desde el principio.

Tampoco se diferenciaban grandemente en sus anhelos de construcción de un sindicalismo de servicios que sirvisiese para disminuir o paliar la situación de precariedad en que se hallaban los trabajadores en un país carente, por entonces, de legislación social alguna.

A tal impulso obedecían iniciativas madrileñas como la constitución de la denominada Aglomeración Cooperativa Casa del Pueblo ${ }^{22}$. La idea se planteaba a finales del 97. Bajo la fórmula de cooperativa obrera - sustentada por las sociedades del Centro-, se buscaba impulsar la acción socialista, al ejemplo de otros correligionarios como los belgas.

La concepción era ambiciosa, se pensaba en abordar todo tipo de servicios contando con los medios que surgieran de la práctica de la cooperación de consumo y de las utilidades y beneficios que ésta pudiera proporcionar. Entre los servicios que podrían ponerse en marcha se contaba, por ejemplo, con los de asistencia facultativa médica o los de instrucción, entre otras cosas con escuelas para niños.... Un programa muy detallado y pergeñado con personas capacitadas para llevar a cabo su gestión, como Quejido o Gómez Latorre, fundadores del partido en el 79.

Pero en el período aquí considerado, las cristalizaciones no serían muy exultantes. En efecto, el 18 de marzo del 99, la Casa del Pueblo instalaba en el Centro Obrero una sección con Café-Comestibles-Librería, a los que pronto se uniría la venta de artículos de vestir y 
calzado así como de combustión e iluminación. Al año siguiente, con el paso al nuevo Centro de Relatores, la Cooperativa renovaba enseres y ampliaba servicios..., pero no pasaba de los objetos de consumo y los beneficios no permitían plantearse nuevas iniciativas.

Las razones distaban más de ser por falta de empeño, como a veces se ha insinuado, que de posibilidades reales de llevarse a cabo, como ponían en evidencia las dificultades de montar desde diversos sindicatos - singularmente los albañiles- prestaciones de socorro y servicios ${ }^{23}$.

La situación de precariedad de medios de vida obrera, limitaba drásticamente los diversos intentos socialistas de constituir sistemas sindicales de previsión. Morato lo pondría en evidencia en múltiples ocasiones. Un sistema de socorros para trabajadores suponía, en Madrid, unos costes mucho mayores que en capitales de otros países. A más bajo nivel de vida, razonaba Morato, corresponde «mayor mortalidad, mayor morbosidad, edad más temprana para la invalidez, más inutilidades y éstas más prematuras», además los salarios cortos presuponen inseguridad en el trabajo, con lo que el socorro de paro forzoso es sumamente difícil.

Y lo ilustraba con dos ejemplos de singular y emblemática significación: los tipógrafos y los albañiles madrileños, incluso en fechas en que el movimiento obrero estaba empezando a consolidarse. Por ejemplo, en 1909, constataba Morato, que los tipógrafos disponían ya de «fondo de resistencia, socorro de viático, de invalidez, en la enfermedad, en la defunción y asistencia médico-farmacéutica para su familia», pagando 96,80 ptas al año, lo que representaba un $8,06 \%$ de su salario. Pero, según sus cálculos, esto en Londres, le suponía a un tipógrafo asociado sólo un 2,77\% del suyo. Similar era lo que acontecía con un oficial albañil madrileño que para fondo de resistencia, socorro en los accidentes y asistencia facultativa para él y los suyos pagaba 52,6 pts., es decir el $5,84 \%$ de su salario, o sea $3,07 \%$ más que el tipógrafo londinense ${ }^{24}$.

La construcción de un sindicalismo de servicios tenía íntima relación con la cuantía y regularidad de los salarios y las condiciones de trabajo y de vida, - por cada 16 defunciones o 160 enfermos en Londres-, se daban 29 y 290 en Madrid, por ejemplo. Conscientes de esas dificultades para poner en marcha tales servicios desde cada sindicato, se plantearían nuevas iniciativas a escala de Centro Obrero. Por ejemplo la constitución de La Mutualidad Obrera Cooperativa médico-farmacéutica y de enterramientos de trabajadores asociados que empezaría a funcionar en 1904 con el fín de cumplir los objetivos de Asistencia Facultativa - dispensario médico quirúrgico, servicio médico a domicilio, 


\section{Santiago Castillo}

servicio especial de partos y farmacia- que ya figuraban como deseables en los estatutos de la Casa del Pueblo en $1897^{25}$.

Como vemos, el socialismo madrileño se encontraba a finales de siglo en una encrucijada. Por un lado, su afán de conseguir reformas en las condiciones de trabajo. Por otro, su deseo de construir paralelamente una red de servicios médicos y de previsión social ante los infortunios: enfermedad, accidente, paro, invalidez... en un país en que la condición obrera estaba en una precariedad extrema.

En realidad los madrileños no hacían sino reflejar la actitud general del socialismo español de finales de siglo. No en vano allí residían sus líderes nacionales, principales artífices de la reelaboración de principios doctrinales y de prácticas que, como ya hemos reiterado en otras ocasiones, se aprecia en el PSOE y la UGT desde mediados los noventa ${ }^{26}$.

Partiendo de la situación económica de atrofia del capitalismo español, adentrándose en análisis del contexto de fuerzas políticas en él existentes y de las clases sociales que actuaban como sus soportes, los socialistas replantean su pensamiento sobre la posibilidad-necesidad de reformas. Reinterpretando para ello su propia praxis y discursos anteriores ${ }^{27}$.

Las líneas generales del nuevo discurso podrían resumirse así: la tarea prioritaria en España es la remodelación del capitalismo. Es imprescindible acelerar y civilizar su desarrollo para ampliar el número de obreros y mejorar sus condiciones de vida. Tales mejoras significan, por otra parte, el incremento del número de obreros revolucionarios. Porque, por la experiencia acumulada, para los socialistas, quienes pueden hacer la revolución en este nuevo contexto, son «los obreros más conscientes, los más enérgicos y los menos explotados y oprimidos». Sólo éstos podrían oponerse a ser vejados, tener tiempo para sus tareas societarias, no estar a merced de presiones sobre venta del voto, etc. La conclusión era evidente y clara, no se puede ir a la revolución con un proletariado famélico e inculto. «Por eso importa mucho disminuir la jornada de trabajo, elevar el salario, dar la mayor instrucción posible a los trabajadores y hacerles tomar parte en la vida política».

"Como programa para que el país salga del presente estado», señalaba Quejido en el mitin del Salón Novedades de Madrid, «la instrucción, la purificación del sufragio y la legislación obrera, en la que figuran como puntos principales la disminución de horas de trabajo y el salario mínimo» ${ }^{28}$.

$\mathrm{Y}$ en esto, la praxis socialista seguía jugando un importante papel. La acción reivindicativa en su doble vertiente de consecución de leyes 
y de práctica cotidiana en las empresas era el eje básico para la transformación industrial del país.

PSOE y UGT habían entrado, por tanto, en una estrategia reformista clara: no renunciaban a la transformación del sistema capitalista, pero durante un período previsiblemente largo, consideraban que debían concentrar sus fuerzas en lograr la existencia de masas obreras de las que poder hacer surgir un ejército «numeroso, instruido y disciplinado», capaz, en suma, de llevar a cabo la revolución en el futuro, incluso, según Morato, sin obligación de un proceso traumático final.

Los socialistas saben, escribía Morato en 1899, que la libertad plena no existe sin desaparecer la desigualdad económica. Pero, aun así, añadía:

«los socialistas estiman que con el solo ejercicio del derecho pueden conseguir mejoras en la situación material de los obreros, alcanzar el respeto de los Poderes a las leyes, propagar sus ideas, y aun, entreven, allá en las lejanías de su ideal, la posibilidad de realizar la hondísima y radical revolución a que aspiran por medios estrictamente legales» 29.

Tal actitud sería apreciada ya por personas que desde otros prismas políticos llegaban a plantear la remodelación del marco jurídico de relaciones laborales, como Canalejas, cuya captación de la proclividad del socialismo europeo, incluido el español, hacia la reforma social, irá acompañada de gestos de atracción como el de contratar a Morato, secretario del Comité Nacional del PSOE como colaborador de su periódico El Heraldo de Madrid ${ }^{30}$.

De ahí también la actitud participativa del socialismo cuando las reformas sociales empezaron a concretarse.

En efecto, como avanzabamos al comienzo de este artículo, a partir de 1900 se inicia en España un verdadero proceso de cambio en la actitud del Estado respecto a las cuestiones sociales. En 1900, bajo un gobierno conservador, Eduardo Dato ponía en vigor dos leyes -sobre el trabajo de mujeres y menores y sobre accidentes de trabajo- que adquirirían rápido desarrollo y relativo cumplimiento. Atrás quedaban décadas de proyectos e incluso una ley -la del trabajo de los niños de 1873 - nunca aplicada.

Las leyes de Dato no iban a quedar aisladas. En 1904 se sumaría a ellas la del descanso dominical, precediendo a otros textos normativos de los años siguientes ${ }^{31}$. Y lo que es más importante, en 1902 un ministro liberal, José Canalejas, proponía la creación de un Instituto del Trabajo, que estará en la base del Instituto de Reformas Sociales 
que, por decreto, acabará aprobando otro gobierno, esta vez conservador, en $1903^{32}$.

Ambos partidos del turno acababan por aceptar la modificación del cuadro jurídico del liberalismo económico estricto que regía hasta entonces. Se entraba, pues, en una nueva etapa. Asumida la práctica de una política laboral permanente desde el Estado, se crearán instituciones de investigación, a la vez que de preparación de su función normativa. A medida que esta última progrese, se exigirían nuevas funciones de control de su efectividad y cumplimiento, que cristalizarán en instituciones, como la Inspección de Trabajo, en años inmediatamente posteriores... España entraba, pues, no sin un cierto retraso, por el camino del intervencionismo científico, a comienzos de siglo.

Se había producido una profunda mutación de actitudes. Desde luego, los móviles del cambio serán muy distintos. Se mezclará el interés de parar la revolución desde arriba para evitar su realización por sectores radicalizados, con el de intentar «integrar» a organizaciones obreras dispuestas al diálogo persiguiendo, además, la modernización del país, sentida como necesaria tras el Desastre de 1898.

En todas las hipótesis, desde el prisma de los partidos de gobierno, el intervencionismo podía ser un preciado útil para evitar males mayores a un sistema cuya esencia había que preservar a ultranza. Desde la óptica socialista significaba, como ya hemos visto, un positivo paso en el camino previsto hacia la radical transformación del mismo. De ahí que el socialismo, sin renunciar, por supuesto, a su propia actividad reivindicativa, paralela y múltiples veces enfrentada a la actitud del Estado en los conflictos, se involucrase de inmediato en el proceso abierto por fin por el Estado, participando, como es sabido, desde un principio en el funcionamiento de instituciones como el IRS ${ }^{33}$.

$\mathrm{Y}$ esto, aunque sus logros se viesen en gran medida aminorados por la estrechez y deficiencia de los canales en que iría cristalizando tal proceso de reforma. Porque, como señalaría el propio Morato, el proceso de reforma social no acabaría de inscribirse en un proyecto mínimamente profundo de reformas generales que conllevasen la integración del movimiento obrero en el sistema ${ }^{34}$, que implicase, pues, entre otras cosas, el respeto y fomento de las prácticas democráticas en general, y en particular por los poderes políticos. «Legalizar» al movimiento obrero, estimulando y fomentando la ampliación de los sectores organizados del mismo que propugnasen la integración de sus reivindicaciones en un proceso de creación de ciudadanía. Faltando esto, a no muy largo plazo, los socialistas madrileños, al igual que 
el conjunto de sus correligionarios españoles verían, como en otro lugar hemos indicado, su anhelo de reforma en gran medida frustrado ${ }^{35}$.

Pero esto sería en un futuro. El Madrid del cambio de siglo, hallaba un movimiento socialista tan deseoso de reformas como presto a colaborar en ellas.

\section{Notas}

1 Sobre ello hemos escrito de forma amplia en Castillo, S., Historia del socialismo español, 1870-1909. Barcelona, 1989; y Hacia la mayoría de edad, 1888-1914. Vol. I' de Historia de la Unión General de Trabajadores. Madrid, 1998.

2 Castillo, S., "Construyendo un partido: La odisea socialista, 1879-1903", en Hispania, 1996, LVI/2, $\mathrm{n}^{\circ} 193$, pp. 623-654.

3 De los 5.154 afiliados del Congreso constituyente de 1888, se había llegado a los 8.000-8.500 en 1892-3, descendiendo después a los 6.000, años 96-7, hasta llegar la reactivación con los 15.000 de finales del 99 .

4 Las cifras de agrupaciones del PSOE pasan de 53 en 1899 a 83 en 1902 y a 150 en 1905. Las de afiliados a la UGT, de 15.000 a 55.000 en el mismo período.

5 Castillo, S., Historia..., opus cit., pp. 75-124, y Hacia la mayorí..., opus cit., pp. 31-64.

6 Para todo lo referente a este período, Morato, Juan José, La cuna de un gigante. Historia de la Asociación General del Arte de Imprimir. Madrid, 1925 [Reed. facsímil, con Estudio preliminar de S. Castillo, Madrid, Ministerio de Trabajo, 1984].

7 Para todo lo referente a este asunto: Castillo, S., "Estudio Introductorio", pp. XXVII-CLXIV, del vol. $1^{\circ}$, de la reedición facsímil, Madrid, 1985, Ministerio de Trabajo, de Reformas sociales. Información oral y escrita publicada de 1889 a 1893 . Madrid, 1889-93, 5 vols.

8 Los barceloneses habían perdido más de la mitad de sus efectivos entre el $\mathrm{I}^{\circ}$ y $\mathrm{II}^{\mathbf{0}}$ congresos. La Federación estaba en precariedad manifiesta. Vide Castillo, S., "Los orígenes de la organización obrera en España: de la Federación de Tipógrafos a la Unión General de Trabajadores", en Estudios de Historia Social, Madrid, 1983, $\mathrm{n}^{\circ}$ 26-27, pp. 19-94.

9 El periódico servía también para poder radicar en Madrid, como su director, a uno de los huelguistas de Ribadeneyra a punto de emigrar, Pablo Iglesias. Para la labor del periódico, Castillo, S., "La travesía del desierto. La prensa socialista, 1886-1900", en Castillo, S. y Otero, L. E. (edits.), Prensa obrera en Madrid 1855-1936. Madrid, 1987, pp. 471-518.

10 La efemérides se plasmaría en una lápida con el nombre de las sociedades que contribuyeron a su creación. Lápida que pasaría a figurar con posterioridad en el Hall de la Casa del Pueblo de Madrid donde estaría, al menos, hasta los primeros años 30. Los asociados al inaugurarse el Centro rondaban los 2.500.

11 El Socialista, $n^{\circ} 670,6-I-1899$, p. 1, "Lo que hemos hecho en 1898».

12 Por entonces las cifras del Centro habían crecido hasta los 35.000 , de ellos unos 25.000 dentro de UGT. Para esta nueva sede véase De Luis Martín, F. y Arias 
González, L., Las Casas del Pueblo socialistas en España (1900-1936), Barcelona, Ariel, 1997.

13 Castillo, S., Hacia la mayoría..., opus cit., pp. 112-114.

14 Tras su Congreso de setiembre de 1899, el Comité Nacional del PSOE lo integraban: Iglesias como presidente Juan J. Morato, tipográfo, como secretario, W. Longares, empleado de comercio, los tipógrafos E. Calvo y L. Vega, el fontanero Agustín de Andrés y Largo Caballero.

15 Se iniciaba en España una situación atípica respecto al socialismo de otros países: la simultaneidad de personas en los órganos rectores de partido y sindicato. Los integrantes de los Comités Nacionales de UGT hasta 1914 en Castillo, S., Hacia la mayoría..., opus cit., pp. 219-222.

16 El texto completo de los distintos programas desde el de 1879 hasta el contituyente del 88, en Castillo, S. Historia..., opus cit. pp. 319-350.

17 Estatutos de UGT, 1888-1914, en Castillo, S., Hacia la mayoría ..., pp. 191-215.

18 El texto de dicha ley en Martín Valverde. A. et al., La Legislación social en la historia de España. De la revolución liberal a 1936. Madrid, 1987.

19 Amplia noticia de ambas campañas en Castillo, S., Organización y Propaganda del PSOE (1886-1895). Tesis doctoral, Facultad de C.C. Políticas y Sociología, U. Complutense, Madrid, 1983, vol. II, cap. IV. pp. 553-586. Un resúmen en Castillo, S. Hacia la mayoría..., opus cit., pp. 50-59.

$20 \mathrm{Si}$ a veces no había fuerza para abandonar el trabajo en día laborable, en otras algunos oficios creían tenerla incluso para presionar, sin acudir a la huelga general, a los patronos, reivindicándoles las 8 horas. Lo harían, con éxito, los canteros recién organizados, 0 , sin lograrlo, los trabajadores en hierro en el Madrid del XIX.

21 Desde entonces, seguirían las fiestas campestres y se mantendrían igualmente las manifestaciones públicas masivas. Presentación a los poderes públicos del conjunto de reivindicaciones que, junto a la clave de las ocho horas, irá pergeñándose año tras año al calor de los congresos internacionales y a tenor de las propias necesidades y coyunturas.

22 Sobre esta institución, De Luis Martín, F. y Arias González, L., Las Casas del Pueblo..., opus cit., pp. 100-104.

23 Byrne J., Work, organization and conflict: The bricklayers of Madrid, 1874-1914. Tesis doctoral, Instituto Universitario Europeo, Florencia, enero 1998.

24 Costos cuya desproporción adquiere aun mayor calado si tenemos en cuenta que por sus cuotas, a diferencia de los londinenses, los tipógrafos madrileños no recibían socorro de paro forzoso ni de emigración, ni al albañil llegaban estos beneficios, ni el socorro en las enfermedades, ni el de invalidez salvo en los accidentes.

25 Sobre la Mutualidad Obrera puede verse mi ponencia «Las prestaciones y socorros sindicales. Logros e impotencias en la España del primer tercio del siglo XX", en XI Simposium de la Sociedad Española de Historia de la Medicina: Enfoques y perspectivas historiográficas en historia de la medicina, Jaraiz de la Vera, 20-22 de setiembre de 2000.

26 Hemos tratado los cambios socialistas del final de siglo, en cuanto al tipo de discurso en Castillo, S., "La travesía...", art. cit. En cuanto a imbricación teoría-praxis en Castillo, S., "Organización y acción política del PSOE hasta 1900", en Anales de Historia, núm. 1, Madrid, 1986, Fundación Pablo Iglesias, pp. 9-33.

27 Véase Castillo, S., Hacia la mayoría..., opus cit., pp. 92-102. 


\section{El socialismo madrileño hace un siglo: Un anhelo.....}

28 "Campaña de propaganda: La reunión del domingo», El Socialista, n ${ }^{\circ}$ 677, 24-II-1899, p. 2. Reforma, pues, tanto del aparato productivo y de la administración del Estado, como del marco general de las relaciones laborales.

29 «Varias cosas se proponen los socialistas practicando sistemáticamente todos los derechos: influir en beneficio de la clase obrera en la marcha de los negocios públicos, educar a esta clase, darle conciencia de sus intereses, llegar a la conquista del Poder político». "En todos los países el abandono de los derechos es nocivo; en España es suicida. Los derechos - dicen [los socialistas]- son arma que hay que manejar, para defenderlos y para la conquista de otros nuevos". Heraldo de Madrid, 9 de setiembre de 1899.

30 Véase el discurso preliminar al libro de Alvarez Buylla, A. y otros, El Instituto del Trabajo. Datos para la reforma social en España. Madrid, R. Fé, 1902 (Reedición facsímil, Madrid, 1986, con "Prólogo» de Santiago Castillo).

31 Para un exhaustivo repertorio de tales normativas y la reproducción de sus textos, véase: Martín Valverde. A. et al., La Legislación..., opus cit.

32 Para la propuesta de Canalejas, véase: Alvarez Buylla, A. y otros, El Instituto..., opus cit. Sobre el IRS, Palacio Morena, J. I., La institucionalización de la reforma social en España 1883-1924. Madrid, 1988.

33 En las primeras elecciones del IRS celebradas en 1904, cinco de los seis vocales serían destacados socialistas-sindicalistas madrileños: Gómez Latorre, Francisco Mora, Largo Caballero, Santiago Pérez y Victoriano Orosa.

34 Para una visión más completa del pensamiento socialista madrileño en los textos de quien era entonces su secretario nacional, Castillo, S., «Juan José Morato. La actitud del socialismo ante la Extensión Universitaria del profesorado ovetense», en Uría, J., (Coor.) Institucionismo y reforma social en España. El Grupo de Oviedo. Madrid, 2000, pp. 162-183.

35 Castillo, S., Hacia la mayoría..., opus cit., pp. 162-178. 